\title{
Temperament in Adulthood Attention Deficit-Hyperactivity Disorder without Bipolar Disorder
}

\author{
Filiz Ozdemiroglu ${ }^{1 *}$, Kadir Karakus ${ }^{1 *}$, Cagdas Oyku Memis ${ }^{1}$, Levent Sevincok ${ }^{1 凶}$, and Sanem Mersin ${ }^{2}$ \\ ${ }^{1}$ Department of Psychiatry, Adnan Menderes University, Aydın, Turkey \\ ${ }^{2}$ Karşıyaka State Hospital, Psychiatry Department, Izmir, Turkey
}

\begin{abstract}
Objective We examined whether some temperamental traits would be associated with persistence of attention deficit-hyperacitivty disorder (ADHD) in adulthood independent from bipolar disorder (BD).

Methods Eighty-one ADHD patients without a comorbid diagnosis of BD were divided into two groups, those with childhood ADHD $(n=46)$, and those with Adulthood ADHD $(n=35)$. The severity of childhood and adulthood ADHD were assessed by using the Wender Utah Rating Scale (WURS-25) and Turgay's Adult ADD/ADHD Diagnosis and Evaluation Scale (DES). Subjects' temperamental characteristics were examined using the Temperament Evaluation of Memphis, Pisa, Paris and San Diego-auto questionnaire (TEMPS-A).

Results The mean scores of WURS-25 were higher in adult ADHD group than in childhood ADHD group ( $\mathrm{p}<0.001$ ). Adult ADHD group had significantly higher scores on cyclothymic $(\mathrm{p}=0.002)$, irritable $(\mathrm{p}<0.0001)$, and anxious $(\mathrm{p}=0.042)$ subscales of TEMPS-A. The scores of WURS-25 in adulthood ADHD group were positively correlated with cyclothymia scores ( $\mathrm{r}=0.366, \mathrm{p}=0.033$ ). Total scores of Turgay's Adult ADD/ADHD DES were positively correlated with cyclothymic $(r=0.354, p=0.040)$, hyperthymic $(r=0.380, p=0.026)$, and irritable $(\mathrm{r}=0.380, \mathrm{p}=0.026)$ subscale scores. Cychlothymic and irritable temperaments were significantly associated with the severity of adulthood symptoms of ADHD.
\end{abstract}

Conclusion We might suggest that cyclothymic and irritable temperaments would predict the diagnosis of adulthood ADHD independent from BD.

Psychiatry Investig 2018;15(3):266-271

Key Words ADHD, Temperament, Adulthood, Childhood.

\section{INTRODUCTION}

Attention deficit-hyperactivity disorder (ADHD) is a developmental childhood-onset psychiatric disorder which is known to continue into adulthood with symptoms of inattention, impulsivity and hyperactivity. ${ }^{1,2}$ While childhood prevalence of ADHD varies between 3 and 12\%, its 1-7.3\% rates at adulthood reveals that childhood ADHD persists into young adulthood in $60-70 \%$ of the cases. ${ }^{3,4}$

The observations demonstrate that ADHD subjects who continue to have their symptoms in adulthood represent a

Received: December 10, 2016 Revised: May 3, 2017

Accepted: June 7, 2017

$\bowtie$ Correspondence: Levent Sevincok, MD

Department of Psychiatry, Adnan Menderes University, Mesrutiyet Street, No:4 Efeler/Aydin, Turkey

Tel: +90 4441256/4120, Fax: +902562121850

E-mail: lsevincok@adu.edu.tr

*They left the university and already work in pravite practice.

(a) This is an Open Access article distributed under the terms of the Creative Commons Attribution Non-Commercial License (http://creativecommons.org/licenses/by$\mathrm{nc} / 4.0$ ) which permits unrestricted non-commercial use, distribution, and reproduction in any medium, provided the original work is properly cited. different group from those that do not manifest the disorder. The presentation of core childhood symptoms of ADHD can change from adolescence to adulthood with less hyperactivity, but with more impulsivity, attentional problems, mood fluctuations, and irritability. ${ }^{5-10}$ In adults, a childhood history of ADHD symptoms is considered important to distinguishing ADHD from other clinical syndromes that can cause similar symptoms, such as mood disorders, substance abuse, and some personality disorders. ${ }^{11-13}$ Number or severity of childhood ADHD symptoms, hyperactivity/impulsivity symptoms, or combined type of ADHD, comorbidity with oppositional defiant disorder (ODD) and conduct disorder (CD), female gender, medication treatment might increase the risk of ADHD persistence, while higher IQ might be a protective factor. ${ }^{7,14-19}$

$\mathrm{ADHD}$ is supposed to be rooted in early development through temperament. ${ }^{20}$ The relationship between the temperament traits and ADHD has been examined in several studies. The children with ADHD showed higher scores on Novelty Seeking $^{21-23}$ and lower scores on Self-Directedness, ${ }^{23-25}$ Cooperativeness, Persistence, ${ }^{24,25}$ and Reward Dependence ${ }^{25}$ compared 
with controls. In adults with ADHD, high Novelty Seeking, Harm Avoidance ${ }^{26-31}$ and low Self-Directedness ${ }^{26}$ have been described. According to previous studies comparing with other temperament and character variables, high Novelty Seeking seems to play a central role in predicting lifetime diagnosis of $\mathrm{ADHD}^{22,32}$ and in mediating the relationship between ADHD and personality disorders, such as borderline personality disorders (BPD). ${ }^{33}$

A high rate of bipolar disorder (BD) comorbidity ${ }^{34,35}$ and bipolar symptoms have been found in adults diagnosed with ADHD. ${ }^{36,37}$ Hence, affective symptoms are considered among essential features of ADHD. ${ }^{38} \mathrm{On}$ the other hand, cychlotymic temperament are strongly related to bipolar spectrum disorder, ${ }^{39}$ and also were found to be more prevalent in adult ADHD patients than in controls and the general population. ${ }^{39,40} \mathrm{Al}-$ though temperament are related to both $\mathrm{BD}$ and $\mathrm{ADHD}$, the relationship of temperament with pure $\mathrm{BD}$ or $\mathrm{ADHD}$ is uncertain yet. In the present study, we hypothesized that some temperamental traits would be predictive for the continuation of ADHD symptoms into adulthood without a comorbid diagnosis of $\mathrm{BD}$. For this aim, we first compared patients whose ADHD symptoms continued (A-ADHD) or disappeared after 18 years old (C-ADHD) in terms of clinical and temperamental properties, and then examined which variables were more likely to be associated with A-ADHD.

\section{METHODS}

\section{Assesments}

Eighty-one subjects (48 women and 33 men) aged between 18 and 65 years with lifetime diagnosis of ADHD were recruited consecutively at the psychiatry out-patient clinics of the Adnan Menderes University Hospital. The subjects were not receiving any stimulant drugs for at least 1 month prior to interviews. Our exclusion criteria were diagnoses of schizophrenia, bipolar disorder, autism spectrum disorders or organic mental syndromes. All patients gave informed consent to participate in the study after the study protocols had been fully explained. The study was approved by the local ethics committee of the Medical Faculty of Adnan Menderes University (Approval number 2014/455).

Lifetime diagnosis of ADHD in total sample was assessed through Structured Clinical Interviews for DSM-IV Axis I Disorders (SCID-I). ${ }^{41,42}$ The patients who reported six symptoms of either inattention or hyperactivity-impulsivity during a 6 months period (DSM-IV criterion A); symptoms of either inattention or hyperactivity-impulsivity before age 7 (criterion B); some impairment in at least two or more settings (like at school or at home) (criterion C); and clinically significant impairment in social, academic or occupational functioning (cri- terion $\mathrm{D})$ were considered to have a diagnosis of $\mathrm{ADHD}(\mathrm{n}=81)$. Thirty-five patients who reported that their ADHD symptoms continued after 18 years old were diagnosed as A-ADHD. Since the remaining 46 patients did not meet the criteria of ADHD after 18 years old, they were considered as having CADHD. We retrospectively assessed the severity of childhood ADHD symptoms in total sample by using the Turkish ver$\operatorname{sion}^{43}$ of Wender Utah Rating Scale (WURS-25) ${ }^{44}$ that is a 25item self-report questionnaire with a 5-point Likert scale based. In order to measure the severity of ADHD in patients with childhood and adulthood ADHD, we used the Turkish ver$\operatorname{sion}^{45}$ of Turgay's Adult ADD/ADHD Diagnosis and Evaluation Scale. ${ }^{46}$

Affective temperamental traits were assessed by Turkish ver$\operatorname{sion}^{47}$ of Temperament Evaluation of Memphis, Pisa, Paris and San Diego auto-questionnaire (TEMPS-A), which was developed by Akiskal and coworkers. ${ }^{48}$ This questionnaire contains subscales of items for the depressive, hyperthymic, cyclothymic, irritable and anxious temperaments to identify dominant affective temperament and to assess the mean scores of affective temperament subtypes. ${ }^{49}$ The original scale consists of 109 items for males and 110 items for females. The Turkish version inquires about lifelong behavior patterns and consists of 99 items to define 5 temperament subtypes: depressive, hyperthymic, irritable, cyclothymic and anxious.

\section{Statistical analysis}

Group differences in demographic variables were computed through chi-square test. The continuous independent data were compared using Student's t-test. To test the inter correlations between the scores of ADHD, and temperament scales, Pearson's correlation analyses were used. Based on the significant correlations obtained, two multiple linear regression analyses were undertaken to examine variance in the scores of WURS-25 and Turgay's Adult ADD/ADHD Scale for 81 participants, using the Stepwise Method. All statistical tests were two-tailed at $\mathrm{p}=0.05$. We used SPSS 15.0 statistical software (SPSS Inc., Chicago, IL, USA) to perform our analyses.

\section{RESULTS}

As indicated in Table 1, there were no significant differences between C-ADHD $(n=46)$ and A-ADHD groups $(n=35)$ in terms of gender, age, marital status, and educational level. The mean scores of WURS- 25 were higher in the A-ADHD group compared to $\mathrm{C}-\mathrm{ADHD}$ group $(\mathrm{p}<0.0001)$. Our results revealed that A-ADHD group had significantly higher scores on cyclothymic $(\mathrm{p}=0.002)$, irritability $(\mathrm{p}<0.0001)$, and anxious $(\mathrm{p}=0.042)$ subscales of TEMPS-A.

Correlational analyses revealed that the scores of WURS- 
Table 1. Comparison of ADHD groups with regard to some demographic, clinical and temperamental variables

\begin{tabular}{|c|c|c|c|c|c|c|c|}
\hline & \multicolumn{2}{|c|}{ C-ADHD (N=46) } & \multicolumn{2}{|c|}{ A-ADHD (N=35) } & \multicolumn{3}{|c|}{ Statistical analyses } \\
\hline & $\mathrm{N}$ & $\%$ & $\mathrm{~N}$ & $\%$ & $\chi^{2}$ & $\mathrm{df}$ & $\mathrm{p}$ \\
\hline Gender & & & & & 0.114 & 1 & 0.73 \\
\hline Female & 28 & 60.9 & 20 & 57.1 & & & \\
\hline Male & 18 & 39.1 & 15 & 42.9 & & & \\
\hline Marital status & & & & & 1.331 & 1 & 0.24 \\
\hline Single & 23 & 50.0 & 22 & 62.9 & & & \\
\hline \multirow[t]{2}{*}{ Married } & 23 & 50.0 & 13 & 37.1 & & & \\
\hline & Mean & SD & Mean & SD & $\mathrm{t}$ & $\mathrm{df}$ & $\mathrm{p}$ \\
\hline Age & 33.47 & 13.01 & 31.22 & 10.04 & 0.84 & 79 & 0.39 \\
\hline Educational level (years) & 10.21 & 3.93 & 10.34 & 3.74 & -0.14 & 79 & 0.88 \\
\hline WURS-25 & 46.45 & 8.40 & 56.11 & 11.23 & -4.25 & 61 & $<0.0001$ \\
\hline \multicolumn{8}{|l|}{ Turgay's adult ADD/ADHD DES } \\
\hline Total & 17.23 & 6.49 & 31.82 & 7.12 & -9.6 & 79 & $<0.0001$ \\
\hline Inattention & 8.80 & 4.12 & 17.54 & 5.27 & -8.36 & 79 & $<0.0001$ \\
\hline Hyperactivity & 5.34 & 3.65 & 9.02 & 4.95 & -3.694 & 60 & $<0.0001$ \\
\hline Impulsivity & 3.10 & 1.81 & 5.17 & 2.62 & -3.976 & 57 & $<0.0001$ \\
\hline Hyperacitivity/impulsivity & 8.45 & 4.57 & 14.28 & 6.87 & -4.33 & 56 & $<0.0001$ \\
\hline \multicolumn{8}{|l|}{ TEMPS-A } \\
\hline Depressive & 9.82 & 3.83 & 11.44 & 3.26 & -1.97 & 77 & 0.052 \\
\hline Cyclothymic & 12.13 & 3.47 & 14.47 & 2.68 & -3.25 & 77 & 0.002 \\
\hline Hyperthymic & 8.64 & 4.68 & 8.00 & 4.30 & 0.62 & 77 & 0.53 \\
\hline Irritability & 7.48 & 3.66 & 10.67 & 3.24 & -4.01 & 77 & $<0.0001$ \\
\hline Anxious & 13.46 & 5.74 & 15.73 & 4.00 & -2.06 & 77 & 0.042 \\
\hline
\end{tabular}

WURS-25: Wender-Utah Rating Scale, TEMPS-A: Temperament Evaluation of the Memphis, Pisa, Paris, and San Diego Autoquestionnaire, Turgay's Adult ADD/ADHD DES: Turgay's Adult Attention Deficit Disorder/Attention Deficit-Hyperactivity Disorder Diagnosis and Evaluation Scale, C-ADHD: childhood- attention deficit-hyperactivity disorder, A-ADHD: adulthood-attention deficit-hyperactivity disorder

Table 2. Correlations of TEMPS-A with severity of childhood and adulthood ADHD symptoms in A-ADHD group

\begin{tabular}{lccccc}
\hline \multirow{2}{*}{ TEMPS-A } & \multicolumn{4}{c}{ A-ADHD (N=35) } \\
\cline { 2 - 3 } & \multicolumn{2}{c}{ WURS-25 } & & \multicolumn{2}{c}{$\begin{array}{c}\text { Turgay's adult ADD/ } \\
\text { ADHD DES }\end{array}$} \\
\cline { 2 - 3 } \cline { 5 - 6 } \cline { 5 - 6 } Depressive & -0.084 & 0.637 & & $-0.354^{*}$ & 0.040 \\
Cyclothymic & $0.366^{*}$ & 0.033 & & $0.354^{*}$ & 0.040 \\
Hyperthymic & 0.069 & 0.700 & & $0.392^{*}$ & 0.022 \\
Irritability & 0.263 & 0.132 & & $0.380^{*}$ & 0.026 \\
Anxious & 0.101 & 0.571 & & -0.032 & 0.858 \\
\hline
\end{tabular}

${ }^{*} \mathrm{p}>0.05$. WURS-25: Wender-Utah Rating Scale, TEMPS-A: Temperament Evaluation of the Memphis, Pisa, Paris, and San Diego Autoquestionnaire, Turgay's Adult ADD/ADHD DES: Turgay's Adult Attention Deficit Disorder/Attention Deficit-Hyperactivity Disorder Diagnosis and Evaluation Scale, A-ADHD: adulthood-attention deficit-hyperactivity disorder

25 in C-ADHD group were positively correlated with cyclothymia $(\mathrm{r}=0.366, \mathrm{p}=0.033)$ subscale scores of TEMPS-A. Total scores of Turgay's Adult ADD/ADHD DES were positively correlated with cyclothymic $(r=0.354, p=0.040)$, hyperthymic $(\mathrm{r}=0.380, \mathrm{p}=0.026)$, and irritable $(\mathrm{r}=0.380, \mathrm{p}=0.026)$ subscale scores of TEMPS-A, and negatively correlated with depressive subscale scores of TEMPS-A ( $\mathrm{r}=-0.354, \mathrm{p}=0.040)$ (Table 2).

Based on expected relationship between the severity of adulthood symptoms of ADHD and temperament, a stepwise linear regression analyses including all significantly correlating variables were conducted with Turgay's Adult ADD/ ADHD DES as dependent variables. For Turgay's Adult ADD/ ADHD DES scores, a significant model $[\mathrm{F}(4,78)=8.927, \mathrm{p}<$ 0.001 ] predicted $32.5 \%$ of the sample outcome variance (Adj. $\left.\mathrm{R}^{2}=0.289\right)$. Four predictors were entered into the model; cyclothymic $(\beta=1.139, \mathrm{t}=3.50, \mathrm{p}=0.001)$ irritable $(\beta=0.913, \mathrm{t}=3.282$, $\mathrm{p}=0.002)$ were significantly associated with higher scores of Turgay's Adult ADD/ADHD DES. Two other predictor variables (depressive and hypertymic temperament) did not significantly contribute to variance with a large effect size $(d=0.406)$ (Table 3).

\section{DISCUSSION}

In the present study, we hypothesized that some temperament traits would be associated with the persistence of ADHD in adulthood even when BD patients were excluded. There are several limitations of this study. First, the sample sizes of 
Table 3. Multiple linear regression analyses of Turgay's adult ADD/ADHD scale and WURS-25 scores ( $N=81)$

\begin{tabular}{|c|c|c|c|c|c|c|c|c|}
\hline Predictor variable & $\mathrm{R}^{2}$ & Adj. $\mathrm{R}^{2}$ & $\mathrm{~F}$ & $\mathrm{p}$ & Constant & Gradient $(\beta)$ & $\mathrm{t}$ & $\mathrm{p}$ \\
\hline \multicolumn{9}{|c|}{ Turgay's adult ADD/ADHD diagnosis and evaluation scale } \\
\hline Model & 0.325 & 0.289 & 8.927 & $<0.001$ & 10.790 & & & \\
\hline TEMPS-A cyclothymic & & & & & & 1.139 & 3.550 & 0.001 \\
\hline TEMPS-A irritability & & & & & & 0.913 & 3.282 & 0.002 \\
\hline TEMPS-A depressive & & & & & & -0.600 & -1.890 & 0.063 \\
\hline TEMPS-A hyperthymic & & & & & & -0.472 & -1.887 & 0.063 \\
\hline
\end{tabular}

WURS-25: Wender-Utah Rating Scale, TEMPS-A: Temperament Evaluation of the Memphis, Pisa, Paris, and San Diego Autoquestionnaire, Turgay's Adult ADD/ADHD DES: Turgay's Adult Attention Deficit Disorder/Attention Deficit-Hyperactivity Disorder Diagnosis and Evaluation Scale

the groups were small to generalize the results. Second, we did not measure the baseline levels of anxiety and depression, which can affect the performance of the patients on the selfrating scales of TEMPS, WURS-25, and Turgay's Adult ADD/ ADHD DES. Current levels of mood and anxiety of the participants are particularly important when interpreting the relationship between anxiety/mood disorders and temperament. For instance, anxiety and mood disorders have shown to correlate to some extent with high scores on harm avoidance. ${ }^{50-52}$ Additionally, we did not assess the subtypes of childhood and adulthood ADHD, and the diagnoses of Axis II disorders since small sample sizes would make it difficult to perform further statistical analysis. In our sample, all subjects $(n=81)$ were assessed for a current diagnosis of ADHD. Among all variables, only the severity of childhood symptoms of ADHD were retrospectively evaluated. Therefore, recall bias might have affected adults' reports of their childhood ADHD symptoms. Despite these limitations, this study indicates that some temperament characteristics of patients would be more likely to be prominent in A-ADHD independent from $\mathrm{BD}$.

One of the main findings of this study was that A-ADHD patients reported more childhood ADHD symptoms on the WURS-25 scale, in accordance with some of the previous studies. ${ }^{16,18,53}$ This result may demonstrate that a more severe course of ADHD during childhood may precede the persistence of ADHD in adulthood.

Cyclothymic temperament is strongly related with increased psychiatric comorbidity, including BD. ${ }^{39}$ Among patients with $\mathrm{BD}$, especially BD II, the cyclothymic temperament has been reported to be the most common temperament trait, and it has been observed that it often precedes the disorder. ${ }^{54,55}$ It is controversial whether persistence of ADHD into adulthood are related to temperament, or overlapping conditions such as mood and anxiety disorders. An association between temperament and ADHD would help understanding of outcomes of C-ADHD in adulthood. A recent study demonstrated that among A-ADHD patients, cyclothymic temperament was associated with more childhood and adult ADHD symptoms. ${ }^{39}$ In our study, we have found that some temperamental traits might be related to the occurence of ADHD symptoms in adulthood. Cychlotymic, irritable, and anxious temperament scores were significantly higher in A-ADHD subjects than those in C-ADHD. Cyclothmic, depressive, hyperthymic, and irritable temperament showed a significant positive correlation with the Turgay's Adult ADD/ADHD DES scores in adults. Stepwise linear regression analysis demonstrated that cyclothymic and irritable traits strongly predicted adulthood scores of ADHD. These results might demonstrate that some temperament traits such as cychlotymia and irritability would not be seen as spesific for BD comorbidity in A-ADHD subjects, and would be among the core features of A-ADHD independent from $\mathrm{BD}$. Since the mean age of our sample seemed to be late for the emergence of $\mathrm{BD}$, we suppose that our results might be representative for pure ADHD. Given the prior studies which demonstrated that depressive, irritable and anxious temperaments were more likely to be related to BPD compared to BD or healthy controls, ${ }^{40,56,57}$ further studies are required to test the relationship between the temperamental traits and personality disorders in adult ADHD subjects. Since we did not assess the Axis II diagnoses, we were not able to examine the relationship between personality disorders and temperament. Regarding high levels of anxious temperament in $\mathrm{BPD}$ and $\mathrm{ADHD}$, it is obvious that particularly $\mathrm{BPD}$ should be evaluated among A-ADHD in the absence of $\mathrm{BD}$.

In conclusion, this study might demonstrate that particularly cyclothymic and irritable temperament would be associated with A-ADHD patients without comorbid diagnosis of BD. Further studies are required to replicate this finding in larger samples including patients with personality disorders.

\section{Acknowledgements}

The authors wish to thank to Dr. Duygu Aslan Kunt for her assistance in data collection.

\section{REFERENCES}

1. Fayyad J, De Graaf R, Kessler R, Alonso J, Angermeyer M, Demyttenaere $\mathrm{K}$, et al. Cross-national prevalence and correlates of adult attention-deficit hyperactivity disorder. Br J Psychiatry 2007;190:402-409.

2. Kessler RC, Adler L, Barkley R, Biederman J, Conners CK, Demler O, 
et al. The prevalence and correlates of adult ADHD in the United States: results from the National Comorbidity Survey Replication. Am J Psychiatry 2006;163:716-723.

3. Barkley RA, Fischer M, Smallish L, Fletcher K. The persistence of attention-deficit/hyperactivity disorder into young adulthood as a function of reporting source and definition of disorder. J Abnorm Psychol 2002; 111:279-289.

4. Simon V, Czobor P, Balint S, Meszaros A, Bitter I. Prevalence and correlates of adult attention-deficit hyperactivity disorder: meta-analysis. $\mathrm{Br}$ J Psychiatry 2009;194:204-211.

5. First MB, Frances A, Pincus HA. DSM-IV-TR: Handbook of Differential Diagnosis. Washington, DC: American Psychiatric Press; 2002.

6. Glockner-Rist A, Pedersen A, Rist F. Conceptual structure of the symptoms of adult ADHD according to the DSM-IV and retrospective Wender-Utah criteria. J Atten Disord 2013;17:114-127.

7. Hart EL, Lahey BB, Loeber R, Applegate B, Frick PJ. Developmental change in attention-deficit hyperactivity disorder in boys: a four-year longitudinal study. J Abnorm Child Psychol 1995;23:729-749.

8. McKay KE, Halperin JM. ADHD, aggression, and antisocial behavior across the lifespan. Interactions with neurochemical and cognitive function. Ann N Y Acad Sci 2001;931:84-96.

9. Ramos-Quiroga JA, Montoya A, Kutzelnigg A, Deberdt W, Sobanski E. Attention deficit hyperactivity disorder in the European adult population: prevalence, disease awareness, and treatment guidelines. Curr Med Res Opin 2013;29:1093-1104.

10. Wilens TE, Biederman J, Spencer TJ. Attention deficit/hyperactivity disorder across the lifespan. Annu Rev Med 2002;53:113-131.

11. Barkley RA. Attention-deficit hyperactivity disorder. Sci Am 1998;279: 66-71.

12. Stein MA, Szumowski E, Blondis TA, Roizen NJ. Adaptive skills dysfunction in ADD and ADHD children. J Child Psychol Psychiatry 1995;36:663-670.

13. Wender EH. Attention-deficit hyperactivity disorders in adolescence. J Dev Behav Pediatr 1995;16:192-195.

14. Biederman J, Faraone SV, Milberger S, Jetton JG, Chen L, Mick E, et al. Is childhood oppositional defiant disorder a precursor to adolescent conduct disorder? Findings from a four-year follow-up study of children with ADHD. J Am Acad Child Adolesc Psychiatry 1996;35:11931204.

15. Cheung CH, Rijdijk F, McLoughlin G, Faraone SV, Asherson P, Kuntsi J. Childhood predictors of adolescent and young adult outcome in ADHD. J Psychiatr Res 2015;62:92-100.

16. Fischer M, Barkley RA, Smallish L, Fletcher K. Executive functioning in hyperactive children as young adults: attention, inhibition, response perseveration, and the impact of comorbidity. Dev Neuropsychol 2005; 27:107-133.

17. Gao Q, Qian Y, He X-X, Sun L, Chang WL, Li YL, et al. Childhood predictors of persistent ADHD in early adulthood: results from the first follow-up study in China. Psychiatry Res 2015;230:905-912.

18. Kessler RC, Adler LA, Barkley R, Biederman J, Conners CK, Faraone SV, et al. Patterns and predictors of attention-deficit/hyperactivity disorder persistence into adulthood: results from the national comorbidity survey replication. Biol Psychiatry 2005;57:1442-1451.

19. Molina BS, Hinshaw SP, Swanson JM, Arnold LE, Vitiello B, Jensen PS, et al. The MTA at 8 years: prospective follow-up of children treated for combined-type ADHD in a multisite study. J Am Acad Child Adolesc Psychiatry 2009;48:484-500.

20. Nigg JT. Temperament and developmental psychopathology. J Child Psychol Psychiatry 2006;47:395-422.

21. Cho SC, Kim JW, Choi HJ, Kim BN, Shin MS, Lee JH, et al. Associations between symptoms of attention deficit hyperactivity disorder, depression, and suicide in Korean female adolescents. Depress Anxiety 2008;25:E142-E146.

22. Donfrancesco R, Di Trani M, Porfirio MC, Giana G, Miano S, Andriola E. Might the temperament be a bias in clinical study on attention- deficit hyperactivity disorder (ADHD)?: Novelty Seeking dimension as a core feature of ADHD. Psychiatry Res 2015;30:227:333-338.

23. Yoo HJ, Kim M, Ha JH, Chung A, Sim ME, Kim SJ, et al. Biogenetic temperament and character and attention deficit hyperactivity disorder in Korean children. Psychopathology 2006;39:25-31.

24. Cho SC, Kim BN, Kim JW, Rohde LA, Hwang JW, Chungh DS, et al. Full syndrome and subthreshold attention-deficit/hyperactivity disorder in a Korean community sample: comorbidity and temperament findings. Eur Child Adolesc Psychiatry 2009;18:447-457.

25. Purper-Ouakil D, Cortese S, Wohl M, Aubron V, Orejarena S, Michel G, et al. Temperament and character dimensions associated with clinical characteristics and treatment outcome in attention-deficit/hyperactivity disorder boys. Compr Psychiatry 2010;51:286-292.

26. Anckarsater H, Stahlberg O, Larson T, Hakansson C, Jutblad SB, Niklasson $\mathrm{L}$, et al. The impact of $\mathrm{ADHD}$ and autism spectrum disorders on temperament, character, and personality development. Am J Psychiatry 2006;163:1239-1244.

27. Gomez R, Woodworth R, Waugh M, Corr PJ. Attention-deficit/hyperactivity disorder symptoms in an adult sample: associations with Cloninger's temperament and character dimensions. Pers Individ Dif 2012; 52:290-294.

28. Instanes JT, Haavik J, Halmoy A. Personality traits and comorbidity in adults with ADHD. J Atten Disord 2016;20:845-854.

29. Faraone SV, Kunwar A, Adamson J, Biederman J. Personality traits among ADHD adults: implications of late-onset and subthreshold diagnoses. Psychol Med 2009;39:685-693.

30. Jacob CP, Romanos J, Dempfle A, Heine M, Windemuth-Kieselbach C, Kruse A, et al. Co-morbidity of adult attention-deficit/hyperactivity disorder with focus on personality traits and related disorders in a tertiary referral center. Eur Arch Psychiatry Clin Neurosci 2007;257:309317.

31. Sizoo B, van den Brink W, Gorissen van Eenige M, van der Gaag RJ. Personality characteristics of adults with autism spectrum disorders or attention deficit hyperactivity disorder with and without substance use disorders. J Nerv Ment Dis 2009;197:450-454.

32. Lynn DE, Lubke G, Yang M, McCracken JT, McGough JJ, Ishii J, et al. Temperament and character profiles and the dopamine D4 receptor gene in ADHD. Am J Psychiatry 2005;162:906-913.

33. Carlotta D, Borroni S, Maffei C, Fossati A. On the relationship between retrospective childhood ADHD symptoms and adult BPD features: the mediating role of action-oriented personality traits. Compr Psychiatry 2013;54:943-952.

34. Millstein RB, Wilens TE, Biederman J, Spencer TJ. Presenting ADHD symptoms and subtypes in clinically refered adults with ADHD. J Atten Disord 1997;2:159-166.

35. Kessler RC, Adler L, Barkley R, Biederman J, Conners CK, Demler O, et al. The prevalence and correlates of adult ADHD in the United States: results from the National Comorbidity Survey Replication. Am J Psychiatry 2006;163:716-723.

36. Milberger S, Biederman J, Faraone SV, Murphy J, Tsuang MT. Attention deficit hyperactivity disorder and comorbid disorders: issues of overlapping symptoms. Am J Psychiatry 1995;152:1793-1799.

37. Galanter C, Pagar D, Davies M, Davies M, Li W, Carlson GA, et al. ADHD and manic symptoms: diagnostic and treatment implications. Clin Neurosci Res 2005;5:283-294.

38. Skirrow C, McLoughlin G, Kuntsi J, Asherson P. Behavioral, neurocognitive and treatment overlap between attention-deficit/hyperactivity disorder and mood instability. Expert Rev Neurother 2009;9:489-503.

39. Landaas ET, Halmoy A, Oedegaard KJ, Fasmer OB, Haavik J. The impact of cyclothymic temperament in adult ADHD. J Affect Disord 2012; 15;142:241-247.

40. Ekinci S, Ozdel K, Oncu B, Colak B, Kandemir H, Canat S. Temperamental characteristics in adults with attention-deficit hyperactivity disorder: a comparison with bipolar disorder and healthy control groups. Psychiatry Investig 2013;10:137-142. 
41. First MB, Spitzer RL, Gibbon M, Williams JB. User's Guide for the Structured Clinical Interview for DSM-IV Axis I Disorders SCID-I: Clinician Version. Arlington, VA: American Psychiatric Pub; 1997.

42. Ozkurkcugil A, Aydemir O, Yıldız M, Danacı E, Koroğlu IV E. Structured clinical interview for DSM-IV axis I disorders-clinical version (SCID-CV) in Turkish: Study of reliability. İlaç ve Tedavi Dergisi 1999; 12:233-236.

43. Oncu B, Olmez S, Senturk V. [Validity and reliability of the Turkish version of the Wender Utah Rating Scale for attention-deficit/hyperactivity disorder in adults]. Turk Psikiyatri Derg 2005;16:252-259.

44. Ward MF, Wender PH, Reimherr FW. The Wender Utah Rating Scale: an aid in the retrospective diagnosis of childhood attention deficit hyperactivity disorder. Am J Psychiatry 1993;150:885-890.

45. Gunay S, Savran C, Aksoy UM. The norm study, transliteral equilivalance, the validity and reliability of the Turkish version of Adult ADD/ ADHD DSM-IV Based Diagnostic Screening and Rating Scale. MÜ Atatürk Eğitim Fakültesi Eğitim Bilimleri Dergisi 2005;21:133-150.

46. Turgay A. Adult Hyperactivity Assessment Scale based on DSM IV (Unpublished Scale). Toronto, Canada: Integrative Therapy Institute; 1995.

47. Vahip S, Kesebir S, Alkan M, Yazici O, Akiskal KK, Akiskal HS. Affective temperaments in clinically-well subjects in Turkey: initial psychometric data on the TEMPS-A. J Affect Disord 2005;85:113-125.

48. Akiskal HS, Placidi GF, Maremmani I, Signoretta S, Liguori A, Gervasi $\mathrm{R}$, et al. TEMPS-I: delineating the most discriminant traits of the cyclothymic, depressive, hyperthymic and irritable temperaments in a nonpatient population. J Affect Disord 1998;51:7-19.

49. Akiskal HS, Akiskal KK. TEMPS: Temperament Evaluation of Mem- phis, Pisa, Paris and San Diego. J Affect Disord 2005;85:1-2.

50. Nery FG, Hatch JP, Glahn DC, Nicoletti MA, Monkul ES, Najt P, et al. Temperament and character traits in patients with bipolar disorder and associations with comorbid alcoholism or anxiety disorders. J Psychiatr Res 2008;42:569-577.

51. Nery FG, Hatch JP, Nicoletti MA, Monkul ES, Najt P, Matsuo K, et al. Temperament and character traits in major depressive disorder: influence of mood state and recurrence of episodes. Depress Anxiety 2009; 26:382-388

52. Svrakic DM, Przybeck TR, Cloninger CR. Mood states and personality traits. J Affect Disord 1992;24:217-226.

53. Guldberg-Kjar T, Sehlin S, Johansson B. ADHD symptoms across the lifespan in a population-based Swedish sample aged 65 to 80. Int Psychogeriatr 2013;25:667-675.

54. Kochman FJ, Hantouche EG, Ferrari P, Lancrenon S, Bayart D, Akiskal HS. Cyclothymic temperament as a prospective predictor of bipolarity and suicidality in children and adolescents with major depressive disorder. J Affect Disord 2005;85:181-189.

55. Rihmer Z, Akiskal KK, Rihmer A, Akiskal HS. Current research on affective temperaments. Curr Opin Psychiatry 2010;23:12-18.

56. Nilsson AK, Jorgensen CR, Straarup KN, Licht RW. Severity of affective temperament and maladaptive self-schemas differentiate borderline patients, bipolar patients, and controls. Compr Psychiatry 2010;51:486491.

57. Walsh MA, Royal AM, Barrantes-Vidal N, Kwapil TR. The association of affective temperaments with impairment and psychopathology in a young adult sample. J Affect Disord 2012;141:373-381. 